\title{
Desenvolvimento Territorial Rural: alguns termos do debate, sistemas agroalimentares localizados e agroturismo
}

\author{
Hoyêdo Nunes Lins*
}

\begin{abstract}
Resumo: A noção de território, que remete a interações sociais baseadas em fatores econômicos e culturais locais, historicamente modelados, adquiriu proeminência no debate sobre a dimensão espacial do desenvolvimento. Com respeito às realidades rurais, a abordagem territorial representa um passo recente em trajetória internacional -e brasileira - de reflexão sobre o desenvolvimento e formulação de políticas para a sua promoção. $\mathrm{O}$ artigo apresenta aspectos da discussão em torno do assunto e explora dois tipos de atividades que ilustram o papel do território, além de mostrar a pertinência da ideia de desenvolvimento territorial rural: as referentes aos sistemas agroalimentares localizados e ao agroturismo.
\end{abstract}

Palavras-chave: Desenvolvimento territorial rural. Sistemas agroalimentares localizados. Agroturismo

Classificação JEL: O18, O13, Z32

Territorial Rural Development: some terms of discussion, local agro-food systems and agro-tourism

\begin{abstract}
The discussion about the spatial dimension of development has witnessed the increasing presence of the notion of territory, referring to social interactions based on local economic and cultural factors, historically shaped. Concerning rural realities, the territorial approach appears as a recent movement in the thinking on development and policy prescription for its promotion, internationally and in Brazil. The article presents some features of the corresponding debate and explores two types of activities which illustrate both the role played by the territory and the usefulness of the idea of territorial rural development: those relating to local agro-food systems and to agro-tourism.
\end{abstract}

Keywords: Territorial rural development. Local agro-food systems. Agro-tourism

JEL Classification: O18, O13, Z32

" Professor Doutor, Titular, do Departamento de Economia e Relações Internacionais da Universidade Federal de Santa Catarina, com participação nos programas de pós-graduação em Economia e em Relações Internacionais dessa universidade. E-mail: hoyedo.lins@ufsc.br 


\section{Introdução}

A noção de território ganhou vulto no debate sobre o desenvolvimento em áreas rurais, em diferentes países. Mudanças registradas nesses ambientes, internacionalmente e no Brasil, em especial uma diversificação das atividades que impõe falar em multissetorialidade, destacam-se entre os fatores que figuram na base desse processo.

Este trabalho inspira-se nessa orientação do referido debate, discutindo os sistemas agroalimentares localizados, compostos por atividades produtivas e serviços ligados à oferta de alimentos com origem territorial, e o agroturismo, em que propriedades agrícolas/rurais incorporam a prática turística às suas atividades. Ambas as manifestações admitem abordagem no marco do chamado desenvolvimento territorial rural, representando, a rigor, ilustrações deste.

O texto está organizado como segue. A próxima parte concentra-se no enfoque do desenvolvimento territorial rural, apontando aspectos gerais do correspondente debate e sua presença no Brasil. Em seguida aborda-se a questão dos sistemas agroalimentares localizados, vistos na perspectiva do tripé território-cultura-inovação, considerando-se experiências brasileiras como exemplos. Na última seção, antes das considerações finais, focaliza-se o agroturismo, lançando-se mão, como ilustrações, de realidades do estado de Santa Catarina, especificamente na área das Encostas da Serra Geral e no planalto serrano.

\section{0 enfoque do desenvolvimento territorial rural: aspectos gerais e situação brasileira}

É crescente a importância atribuída ao território na abordagem do desenvolvimento no meio rural, seja em análises ou em iniciativas de promoção. Dizer território, assinale-se, significa referir a espaço vivido e percebido, cujo sentido não se confunde com a ideia de local: esta "[...] remete à escala enquanto o território remete ao modo de construção pelos atores, qualquer que seja a escala” (PECQUEUR, 2009a, p. 206).

\subsection{A "emergência" do território}

A noção de território, relativa ao plano mesoeconômico de agregação dos indivíduos (com elementos de contiguidade e recursos materiais ou simbólicos, refletindo história e cultura), e as derivações territorialidade (ressaltando os atributos ligados às interações dos indivíduos com seus ambientes) e territorialização (evocando ação coletiva, intenção e (re)produção do território) ganharam espaço nas abordagens sobre o desenvolvimento em áreas rurais. Entre as razões, estão as mudanças ocorridas nesse meio, com diversificação de atividades rumo a uma efetiva multissetorialidade.

Com efeito, cada vez mais, "Ruralidade é um conceito de natureza territorial 
e não setorial [...]” (ABRAMOVAY, 2001, p. A-3). Para Kageyama (2004, p. 388), "O desenvolvimento rural tem de específico o fato de referir-se a uma base territorial [...] na qual interagem diversos setores produtivos e de apoio, e nesse sentido trata-se de um desenvolvimento 'multissetorial'”.

Em termos internacionais, têm importância nesse debate os trabalhos de Pecqueur $(2001 ; 2005 ; 2009 b)$, onde o território é visto como resultado de construção e delimitação pelas práticas dos atores sociais, incluindo as estruturas de regulação. Para equacionar problemas geralmente comuns e incidentes na escala mesoeconômica - diferente da individual e da global -, esses atores conjugam ações de discriminação do território e, como decorrência, de criação deste.

Crucial é o processo de transformação dos recursos territoriais em ativos específicos, fontes de diferenciação no embate da concorrência. Essa ideia de especificidade, relacionada com a ativação de recursos territoriais intransferíveis, escora-se “[...] numa concepção cultural da produção (que é ligada às características culturais e aos modos de organizações de seus atores) que corresponde a uma relação de coordenação anterior à troca capitalista de bens e serviços padronizados” (PECQUEUR, 2005, p. 11).

O destaque para a dimensão territorial aparece, por exemplo, em tentativas de vislumbrar um novo modelo de economia rural para áreas com problemas, causados por processos gerais ou pelo próprio declínio das atividades locais. Escrevendo sobre o Reino Unido nessa perspectiva, Ray (2002) explora a ideia de "acumulação reflexiva”, que considera a influência dos símbolos (logo, da subjetividade) sobre a produção e o consumo, e destaca a importância das redes de confiança.

A dimensão territorial escora também análises sobre os reflexos em áreas rurais da crise econômica resultante do estouro da bolha imobiliária nos Estados Unidos, em 2008. Estudando a Andaluzia (Espanha), Sánchez-Zamora, Gallardo-Cobos e Ceña-Delgado (2014) observaram que dinâmicas territoriais bem sucedidas refletiam a estabilidade de fatores territoriais quanto a: diversificação econômica, solidez e diversidade na agricultura, acesso a serviços, presença e uso adequado de recursos naturais e governança.

Na América Latina, Mora e Sumpsi (2003) miram o plano territorial quando propõem novos enfoques e perspectivas para o desenvolvimento no meio rural. Perante os desafios da globalização e as mudanças estruturais em vários países, esses autores ressaltam o problema dos vazios institucionais, ao discutirem o papel de agências governamentais, organismos internacionais e organizações não governamentais quanto às possibilidades de superação das dificuldades. Igualmente tratadas são as questões de organização e participação social, cruciais nas estratégias de desenvolvimento na escala territorial. 


\subsection{Tangenciando o debate e as ações no Brasil}

Também no Brasil o território ganhou destaque no debate sobre o desenvolvimento em áreas rurais. Desde os anos 1980 fortaleceu-se a ideia de desenvolvimento rural sustentável, com foco na sustentabilidade e na equidade social. Posteriormente, sobressaiu o desenvolvimento local, refletindo tendência à descentralização das ações do Estado e a proliferação de análises sobre os desafios da globalização, com realce para a agricultura familiar e as ações associativas (NAVARRO, 2001).

No período atual, é principalmente de desenvolvimento territorial rural que se trata, estando as atenções voltadas para

[...] o espaço de ação em que transcorrem as relações sociais, econômicas, políticas e institucionais. Esse espaço é construído a partir da ação entre os indivíduos e o ambiente ou contexto objetivo em que estão inseridos. Portanto, o conteúdo desse espaço é entendido como o território. (SCHNEIDER, 2004, p. 99).

O palco da emergência desse enfoque no país exibe grandes transformações no meio rural. Uma delas refere-se à multiplicação de atividades urbanas nessas áreas, dificultando a separação analítica entre o meio urbano e o rural. Mudanças econômicas e políticas, com seus reflexos sociais, além da tendência à pluriatividade, também nutriram o debate. Assim, desde os anos 1990, novos contornos surgiram até nas ações de promoção desse desenvolvimento, crescentemente caracterizadas por referências ao território (SCHNEIDER, 2010).

Assinale-se que os trabalhos de Veiga (2001; 2002a,b) e Abramovay (2000; 2002; 2009) tiveram influência nas discussões sobre a dimensão territorial do desenvolvimento em meio rural no Brasil. Agricultura familiar, capacidade empreendedora e inovativa, pluriatividade, tecido institucional ativo e sustentabilidade são questões usuais. Igualmente sublinhados são os vínculos permeados de reciprocidade e solidariedade nas comunidades rurais, como observado em áreas do nordeste brasileiro (SABOURIN, 2009-2010).

$\mathrm{O}$ assunto exibe permanência na agenda. Em recente livro sobre a questão rural no Brasil, Favareto (2014) destaca as grandes mudanças ocorridas nos componentes tradicionais da ruralidade. Estas referem-se à contiguidade homem-natureza (novos usos dos recursos naturais), às interações com o meio urbano (economias dos espaços rurais diversificadas e integradas intersetorialmente) e aos vínculos entre pessoas (com heterogeneidade crescente, reflexo de maior integração entre mercados). $\mathrm{Na}$ introdução ao livro, Navarro et al. (2014, p. 74) sugestivamente assinalam: "Forma-se, assim, uma nova ruralidade", a chave de leitura da qual, vale acrescentar, há de ser a abordagem territorial.

Também as liturgias governamentais incorporaram o desenvolvimento territorial rural. Os Consórcios de Segurança Alimentar e Desenvolvimento Local (CONSADs), criados em 2003 no marco do Programa Fome Zero, representam 
uma adequada ilustração: espelharam o reconhecimento de que os problemas das populações carentes transbordam os limites municipais e que, apesar das dificuldades nas ações de equacionamento condizentes, a dimensão a ser privilegiada deveria ser a territorial (ORTEGA, 2007).

Texto do Ministério do Desenvolvimento Agrário (MDA) dava o tom da ação federal: "O enfoque territorial é uma visão essencialmente integradora de espaços, atores sociais, agentes, mercados e políticas públicas de intervenção. Busca a integração interna dos territórios rurais e destes com o restante da economia nacional [...]”. (BRASIL, 2003, p. 26).

Evidência maior da importância atribuída a essa escala foi a criação da Secretaria de Desenvolvimento Territorial pelo MDA. Isso foi corroborado com o programa Territórios da Cidadania, surgido em 2008 para congregar ações interministeriais com recursos geridos pela Casa Civil do Governo Federal. Observando essas iniciativas, principalmente o funcionamento dos Colegiados de Desenvolvimento Territorial - fóruns intermunicipais criados para mobilizar os agentes do território e promover a elaboração de projetos de melhoria das condições de vida e trabalho locais - , Favareto concluiu que,

[...] em uma década de políticas de desenvolvimento territorial, conseguiu-se impor este tema à agenda dos agentes públicos e de movimentos sociais e organizações não-governamentais ou de assessoria. Conseguiu-se criar formas de mobilização das forças organizadas da agricultura familiar em âmbito microrregional. E conseguiu-se um maior grau de controle social sobre os investimentos direcionados à agricultura familiar. Mas ainda se está longe de [...] ensejar articulações consistentes envolvendo o conjunto das forças vivas dos territórios e que respondem por sua dinâmica. (FAVARETO, 2009-2010, p. 58).

\section{Território, cultura, inovação: o ângulo dos sistemas agroalimentares localizados}

Uma estimulante vertente do debate sobre o desenvolvimento territorial rural refere-se à noção de sistema agroalimentar localizado (SAL), relativa a feixes de atividades produtivas e serviços articulados (produção primária e agroalimentar, comércio, restaurantes), vinculados a territórios específicos por conta de suas características.

\subsection{Caracterização dos sistemas agroalimentares localizados}

Esses sistemas caracterizam-se pela oferta de produtos cuja origem costuma ser indicativa de qualidade, concorrendo para esta as práticas de manutenção do território e de seus atributos. Têm papel central os recursos próprios dos territórios, ou seus ativos específicos, de que se valem os agentes locais. Assinale-se que esses sistemas não se confundem com os territórios. Estes amparam os SAL por 
representarem origem de ativos específicos, externalidades de que se beneficiam os agentes. O conjunto de ativos específicos constitui a territorialidade, um recurso fundamental do território para as atividades produtivas desses sistemas.

Esses ativos específicos vinculam-se aos componentes sociais e culturais do território, mostrando-se inseparáveis da história local. Incluem recursos como o conhecimento tácito disseminado no tecido produtivo (ativo específico de tipo cognitivo, que afeta as inovações) e também a identidade sociocultural, associada ao passado comum dos agentes e tributária de confiança e de condutas de reciprocidade, ambas nutrientes de ações coletivas que impulsionam processos de aprendizagem e inovação. Também faz parte o tecido institucional, suporte das atividades locais e protagonista de coordenação.

Ativos específicos próprios ao setor agroalimentar e às áreas rurais abrangem o know-how para transformar produtos primários, com base no conhecimento enraizado e compartilhado localmente (representando capital humano), e a proximidade entre os consumidores e o alimento que tipifica um determinado sistema. Essa proximidade não é necessariamente física, e sim relativa à apreciação e valorização do produto, representando fidelidade no consumo vinculada ao conhecimento dos consumidores, que identificam e valorizam aspectos de origem do alimento.

Daí a importância do tipo de ambiente em que ocorre a produção, considerando-se a qualidade dos recursos naturais ou a identidade cultural. Pode-se dizer que o território comporta uma imagem, sendo ela própria um estratégico atributo, na forma de ativo específico que resulta de práticas locais e constitui expressão da cultura.

$\mathrm{O}$ reconhecimento da qualidade é fator de diferenciação que favorece o desenvolvimento dos SAL. Isso é sobremodo relevante quando há interações de construção social da qualidade, já que a qualidade territorial é estribada, além dos recursos naturais e da paisagem (capital natural), também nos resultados do exercício do know-how (capital humano) no processo de transformação agroindustrial de produtos primário. Sobre tais interações de construção social da qualidade podem ser erigidas convenções relacionadas à origem territorial do produto, como assinala Requier-Desjardins (2002). Interligando produtores primários, agentes que protagonizam transformação agroalimentar, distribuidores e consumidores, esses vínculos representam, eles próprios, ativos específicos territorializados.

Cabe aludir, sobre isso, à ideia de capital social, que capta a presença de vínculos locais expressos tanto em sistemas de normas e convenções como em estruturas sociais. Esses vínculos lubrificam quer a difusão dos conhecimentos, quer os processos de inovação relacionados à transformação agroindustrial. Merece realce especial o problema da inovação, percebida como socialmente construída: a inovação deriva de relações de interdependência e

mostra-se escorada em conhecimentos locais e em aprendizagem coletiva, refletindo o funcionamento de instituições e suas estruturas de governança.

Os agentes dos SAL não operam só no meio rural. Os produtores primários e beneficiadores mantêm relações a montante - com fornecedores de insumos - e a ju- 
sante - com comerciantes - que podem incidir fora dessas áreas. $\mathrm{O}$ mesmo se observa na estrutura institucional, quanto aos centros de pesquisa e à infraestrutura tecnológica. Assim, o espaço dos SAL não tem conteúdo somente geográfico e nem é plasmado por determinações limitadas a essa esfera: sua posição é a "confluência” do território, cujos ativos específicos representam a territorialidade, com a cadeia de produção-distribuição-consumo do alimento de que se trata, conforme estilizado na figura 1.

Figura 1 - Sistema Agroalimentar Localizado: convergência do território com a cadeia produção-comercialização-consumo

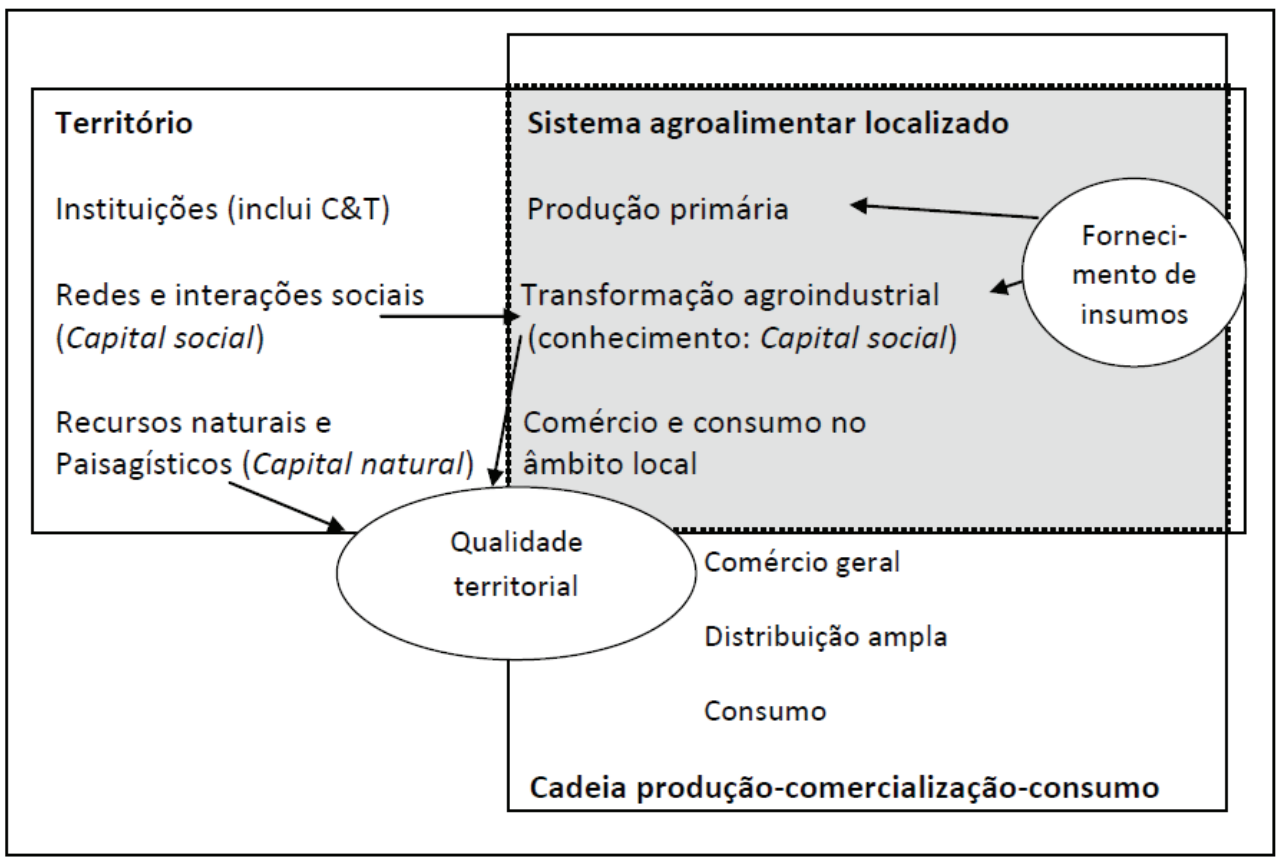

Fonte: elaborado pelo autor com base em Requier-Desjardins e Rodriguez (2002), com adaptação

\subsection{Indagando sobre realidades territoriais à luz da noção de SAL}

Sistematizam-se a seguir aspectos principais de quatro trabalhos cuja realização foi inspirada, de uma forma ou de outra, na problemática dos SAL. Embora se refiram a produtos muito diferentes entre si, e tenham sido realizados em períodos distintos e com métodos próprios de obtenção de informações (sendo o autor deste artigo responsável por um dos trabalhos considerados), esses estudos foram selecionados por se mostrarem sugestivos sobre o quanto a noção de SAL pode servir de chave de leitura em abordagens sobre situações concretas. De fato, em todos têm grande realce as questões de cunho sociocultural e histórico e a importância dos recursos territoriais e dos ativos específicos. 


\subsubsection{Ostras e mexilhões cultivados em Santa Catarina}

Santa Catarina é destaque na maricultura brasileira desde o início dos anos 1990, sobretudo em relação a moluscos (ostras e mexilhões). O setor cresceu em área cujo capital natural inclui águas litorâneas favoráveis, e tanto o capital humano como o capital social refletem a cultura pesqueira e a familiaridade com o mar.

Esses atributos foram valorizados em ações complementares da Universidade Federal de Santa Catarina e da Empresa de Pesquisa Agropecuária e Extensão Rural de Santa Catarina, do governo estadual, a primeira com pesquisas sobre cultivo, a segunda com extensionismo que disseminou a nova atividade no litoral catarinense. A importância do capital humano ligado à herança pesqueira foi logo evidenciada: o ativo específico de tipo cognitivo incrustado nas localidades propiciou fértil entrelaçamento entre pesquisadores e produtores (LINS, 2006).

Redes sociais, com vínculos verticais e horizontais, costumam favorecer a propagação do conhecimento e a dinâmica das inovações nos SAL, como assinalado anteriormente. $\mathrm{Na}$ experiência de maricultura em foco, as relações verticais viram surgir empresas fornecedoras de insumos e outros materiais, e também casos de moradores que passaram a prestar serviços aos maricultores (fazendo reparos em equipamentos e materiais) ou dedicaram-se à comercialização, como intermediários entre produtores e restaurantes/bares ou diretamente aos consumidores. A jusante do cultivo, apareceram atividades de defumação de moluscos, transformação em formas semiprontas e embalagem com óleo ou molho vinagrete, geralmente para restaurantes e bares locais, e mesmo, embora minoritariamente, para clientes de São Paulo.

A consolidação do setor ensejou maior cuidado com o ambiente costeiro, pois a qualidade das águas litorâneas é um requisito essencial. Cresceu o sentido de preservação nas comunidades, com o monitoramento e o controle de práticas capazes de prejudicar a maricultura. Pode-se referir, assim, à disseminação de condutas de manutenção do capital natural, fundamentais para a qualidade territorial no tocante à atividade em questão. Também nisso cruzaram-se interações no plano horizontal (monitoramento no seio das comunidades, para cercear e coibir comportamentos deletérios) e no plano multilateral (envolvimento de instituições estaduais).

Mas a cooperação entre maricultores e, principalmente, sua organização em associações permaneceram esferas carentes de melhores resultados. $\mathrm{O}$ mesmo pode ser dito sobre os conflitos de uso em trechos do litoral, intensificados com a prática da maricultura.

\subsubsection{Leite e queijo em Nossa Senhora da Glória (SE)}

Também admite abordagem à luz do debate sobre os SAL a experiência da bacia leiteira cujo centro de gravidade é o município de Nossa Senhora da Glória, no estado do Sergipe, estudada por Cerdan e Sautier (2001). Esse território tem longa tradição pecuarista, traduzida em produção leiteira e de queijo em formas típicas do 
nordeste do Brasil, destacando-se o queijo de coalho.

A produção de queijo representa manifestação de identidade sociocultural, ligada a uma duradoura sedimentação de conhecimentos envolvendo queijarias artesanais. $\mathrm{O}$ processo favoreceu a especialização e o aprimoramento dos produtores e a disseminação de conhecimento: pequenas fábricas surgiram e se multiplicaram, definindo o perfil específico da bacia leiteira, com agentes em produção leiteira, transformação em queijo (e outros derivados) e comercialização.

Foram importantes as redes de ação coletiva, envolvendo famílias com presença tanto em produção leiteira como na transformação. As redes eram também de cunho profissional, em vínculos verticais - envolvendo comerciantes de queijo e seus fornecedores e fabricantes de queijos e os produtores de leite - , e horizontais - principalmente com interações entre os comerciantes, recobrindo trocas de informações sobre preços; todavia, as relações entre fabricantes de queijo eram rarefeitas, talvez pela desconfiança ou a concorrência. Essas redes eram igualmente institucionais, abrangendo serviços técnicos, atividades de pesquisa e esquemas de apoio que atingiam o crédito.

Mesmo heterogêneas e hierarquizadas, essas redes tiveram importante papel no aprimoramento e expansão da fabricação de queijo, influenciando os vínculos da cadeia produtiva. Tais interações frutificaram na criação de um organismo de coordenação e igualmente no tocante à utilização, pelos integrantes do sistema, dos recursos específicos ao local. As redes profissionais favoreceram a inovação em produto, como ilustrado pelo queijo de coalho pré-cozido, incorporado a partir de uma oportunidade percebida localmente. Outro exemplo foi a introdução do queijo tipo mozzarella, por conta de uma demanda pontual originada em pizzarias de São Paulo. Essas inovações representaram a difusão de novos conhecimentos e contribuíram para a ampliação das possibilidades do sistema, fortalecendo a qualidade territorial.

De todo modo, carências em termos de ação coletiva, ou de cooperação, permaneciam marcantes no local. Como em outras experiências registradas na literatura, esse problema mostrava-se merecedor de particular atenção.

\subsubsection{Marolo em Alfenas (MG)}

Situada no sul de Minas Gerais, a área de Alfenas abriga numerosas pequenas propriedades rurais com atividades como cafeicultura, olericultura, bovinocultura leiteira e avicultura. O marolo, um fruto carnoso, é parte da cultura alimentar local, a rigor um elemento básico da identidade regional, comercializado geralmente em feiras locais e por vendedores ambulantes.

Os pequenos produtores rurais são os principais agentes nas atividades ligadas ao marolo, segundo Rezende, Cândido e Malafaia (2012). A pesquisa realizada por esses autores mostrou que pouco menos de $1 / 3$ desses produtores detêm plantios comerciais desse fruto, e que a maioria (60\%) é extrativista, só uns poucos operando em cultivo e extração, simultaneamente. Todavia, as atividades locais não 
se limitam ao extrativismo ou ao cultivo, pois, em boa parte dos casos, os agentes também atuam como comerciantes e processadores dos frutos.

Quem vende in natura abastece terceiros que fazem processamento, do que resultam polpa, doces, licores, refrescos, geleias e sorvetes. Produtores que também processam, comercializam, sobretudo, a polpa, mas igualmente doces e licores. Todos esses produtos vão para comerciantes que os fazem atingir mercados em Belo Horizonte, São Paulo e Campinas, principalmente. Segundo o referido estudo, 1/4 dos produtores têm no marolo a principal fonte da renda familiar, e para os demais o produto representa complementação.

O conhecimento sobre as técnicas de cultivo e de colheita, as formas de transporte e armazenagem ou o processamento origina-se na experiência pessoal de cada agente. Tal característica é merecedora de realce, remetendo a questões de ordem sociocultural e também ao que se falou anteriormente sobre ativos específicos de tipo cognitivo incrustados nos territórios.

Contudo, é escasso o conhecimento científico sobre o assunto, o que ressalta o valor de interações com o aparato de ciência e tecnologia (próximo ou distante) para o vislumbre de novas possibilidades. Também faz falta uma melhor cultura organizacional, pois os produtores atuam em situação de certo isolamento. A dispersão e a escassa ação coletiva não favorecem os processos de inovação e podem afetar os resultados econômicos. Políticas de promoção haveriam de propiciar melhorias: em que pesem as dificuldades para organizar os produtores, a articulação território - cadeia produtiva está presente na área, acenando positivamente.

\subsubsection{Carne bovina na Campanha Meridional Gaúcha (RS)}

A tradição da Campanha Meridional Gaúcha em pecuária bovina de corte baseia-se, antes de tudo, na presença de um bioma favorável, o pampa. Igualmente fundamental é o conhecimento tácito existente sobre as lides campeiras e o manejo e abate de animais, enraizado no território e longamente acumulado.

Tem importância, para as atividades correspondentes, a Associação dos Produtores de Carne Pampa Gaúcho da Campanha Meridional (APROPAMPA). Seu papel ganhou particular evidência quando a Indicação de Procedência (IP) da carne bovina local foi instituída, em 2006, designando diferenciação de produto: vários municípios são recobertos por essa IP, apresentando diversidade de gramíneas e criação de animais (Angus e Hereford) de forma extensiva. Esses animais são alimentados com pasto e têm seus movimentos obrigatoriamente rastreados.

A atividade evoluiu em meio a vínculos entre produtores e destes com o tecido institucional da região. Essa base é composta, além da APROPAMPA, pelo Serviço Brasileiro de Aprendizagem Empresarial, o Serviço Nacional de Aprendizagem Rural, a Federação de Agricultura do Rio Grande do Sul, a Universidade Federal do Rio Grande do Sul e a Empresa Brasileira de Pesquisa Agropecuária (MALAFAIA; BARCELLOS, 2007). 
A APROPAMPA, que monitora o processo de certificação, aglutina produtores rurais, frigoríficos, comerciantes e outros agentes ligados à bovinocultura, cujas ações articulam-se na preservação e na proteção da qualidade e da imagem dos produtos (carne, couro e derivados). Destacam-se as atividades de um frigorífico instalado em Bagé, que lançou a marca "Força do Rio Grande", com diferentes cortes de carne. A imagem regional é também promovida pela realização da Exposição Feira de Animais e da Festa Internacional do Churrasco.

Assim, conjugam-se recursos específicos do território e vínculos que autorizam falar em sistema, em grande medida devido à participação de agentes cuja conduta é permeada do sentido de associação. Mas isso não significa ausência de problemas, e tampouco que aprimoramentos sejam desnecessários. Por exemplo, como assinalado por Malafaia e Barcellos (2007), diversos produtores padeciam de baixa capitalização no período do estudo realizado por esses autores, dificultando melhorias tecnológicas. Também havia espaço para inovações que proporcionassem menores custos e maior diferenciação de produto (com aumento da competitividade), e igualmente para prospecção e exploração de novos mercados.

\section{Território, cultura, inovação: o ângulo do agroturismo}

Com destaque entre as experiências que representam diversificação das práticas turísticas, o turismo rural - e, neste, o agroturismo - tem como base, geralmente, a atratividade de atmosferas bucólicas junto a contingentes urbanos que associam busca de novas vivências à presença em ambientes distintos das realidades citadinas, participando dos respectivos afazeres e observando-lhes os costumes.

\subsection{Agroturismo: considerações gerais}

O agroturismo é um segmento do turismo rural que envolve propriedades em busca de outras possibilidades na geração de renda e oportunidades de trabalho. Participar da oferta requer ações ligadas à hospedagem, adaptando imóveis existentes ou instalando novas estruturas, e à alimentação, com extensão ou melhoria da capacidade de produzir refeições, até com pequenos restaurantes que exploram a culinária típica. Também faz parte a valorização de produtos locais, em estruturas agroindustriais familiares ou comunitárias, assim como a organização de lazer e entretenimento escorados no patrimônio paisagístico e socioambiental das localidades.

Uma característica maior dessa modalidade turística é a participação dos visitantes na faina diária das propriedades rurais e a apreciação das - a rigor, o envolvimento nas - manifestações de natureza cultural e folclórica. Cavaco (1999, p. 118-119) diz tratar-se de um “[...] subproduto da agricultura, que atrai pela paisagem, em ligação com os sistemas tradicionais, pela vida animal [...], pelas condições de vida e trabalho, pelo funcionamento das comunidades rurais [...]”. 
A relação da presença desse turismo com o desenvolvimento no meio rural, frequentemente postulada, pode expressar-se em aumento da renda das propriedades, geração de postos de trabalho, atividades de apoio e fortalecimento das finanças públicas, repercutindo em inibição das migrações campo-cidade. Visto por essa perspectiva, esse turismo não difere muito de outras atividades capazes de dinamização econômica, estimulando o desenvolvimento em áreas rurais. Mas há particularidades que convidam a olhar para outros aspectos, além daqueles tradicionalmente considerados, envolvendo a quantidade de postos de trabalho gerados e o incremento na renda.

Com efeito, ostenta grande importância, além do meio ambiente, também a cultura, expressão e determinante do modo de vida, evidenciando a centralidade dos patrimônios natural, histórico e sociocultural. Daí que "sustentável" tem força como adjetivação e "território" é referência para o discurso e a ação: o desenvolvimento deve também representar a manutenção de recursos territoriais como a qualidade ambiental e paisagística, de uma parte, e os elementos da cultura, de outra.

A complementaridade dos fatores, a diversidade dos agentes e o compartilhamento dos recursos, em contexto de existência combinada de atributos, atividades, produtos e possibilidades, sustentam análises sobre o desenvolvimento no meio rural em que sobressai a noção de "cesta de bens e serviços", introduzida por Pecqueur (2001). A expressão remete às possibilidades de criação, pelos agentes do território, de estratégia para produzir e disponibilizar uma oferta múltipla e articulada de vários bens e serviços, vinculada a um espaço particular, isto é, permeada pela cultura e a história do local. O território emerge, nesse processo, com significado inclusive simbólico, além de representar origem e contexto indicativos de qualidade, um aspecto que favorece a aceitação dos vários produtos e serviços oferecidos.

$\mathrm{O}$ agroturismo geralmente se destaca na combinação de produtos e serviços territoriais, integrando a assinalada "cesta", com enraizamento que chancela qualidade na percepção dos consumidores. Os itens ofertados são complementares e interdependentes, refletindo-se na produção e no consumo em escala territorial: "O consumidor busca, na realidade, uma especificidade que não se baseia só nas características do produto tomado isoladamente, mas numa combinação específica ao território considerado.” (PECQUEUR, 2001, p. 44).

Desse modo, estratégias solidárias de produtores diferentes, fazendo o grupo mostrar características de “[...] um coletivo de produção" (PECQUEUR, 2001, p. 46), subjazem ao aumento da renda territorial. Cooperação e governança devem ser, portanto, aspectos considerados na abordagem desse turismo, tanto quanto da relação deste com o desenvolvimento nas áreas rurais implicadas. 


\subsection{Examinando realidades agroturísticas: Santa Catarina como laboratório}

Exploram-se nesta seção duas experiências de agroturismo no estado de Santa Catarina, abordadas com base em pesquisa bibliográfica e documental. Uma refere-se à área das Encostas da Serra Geral, no sudeste catarinense, a outra, ao que aparece em documentos oficiais e na divulgação turística como Região Serrana. Em ambas, apontadas na figura 2, observam-se aspectos que sobressaem no debate sobre o desenvolvimento territorial rural, nos termos referidos anteriormente.

Figura 2 - Localização dos municípios das Encostas da Serra Geral e da Região Serrana, em Santa Catarina

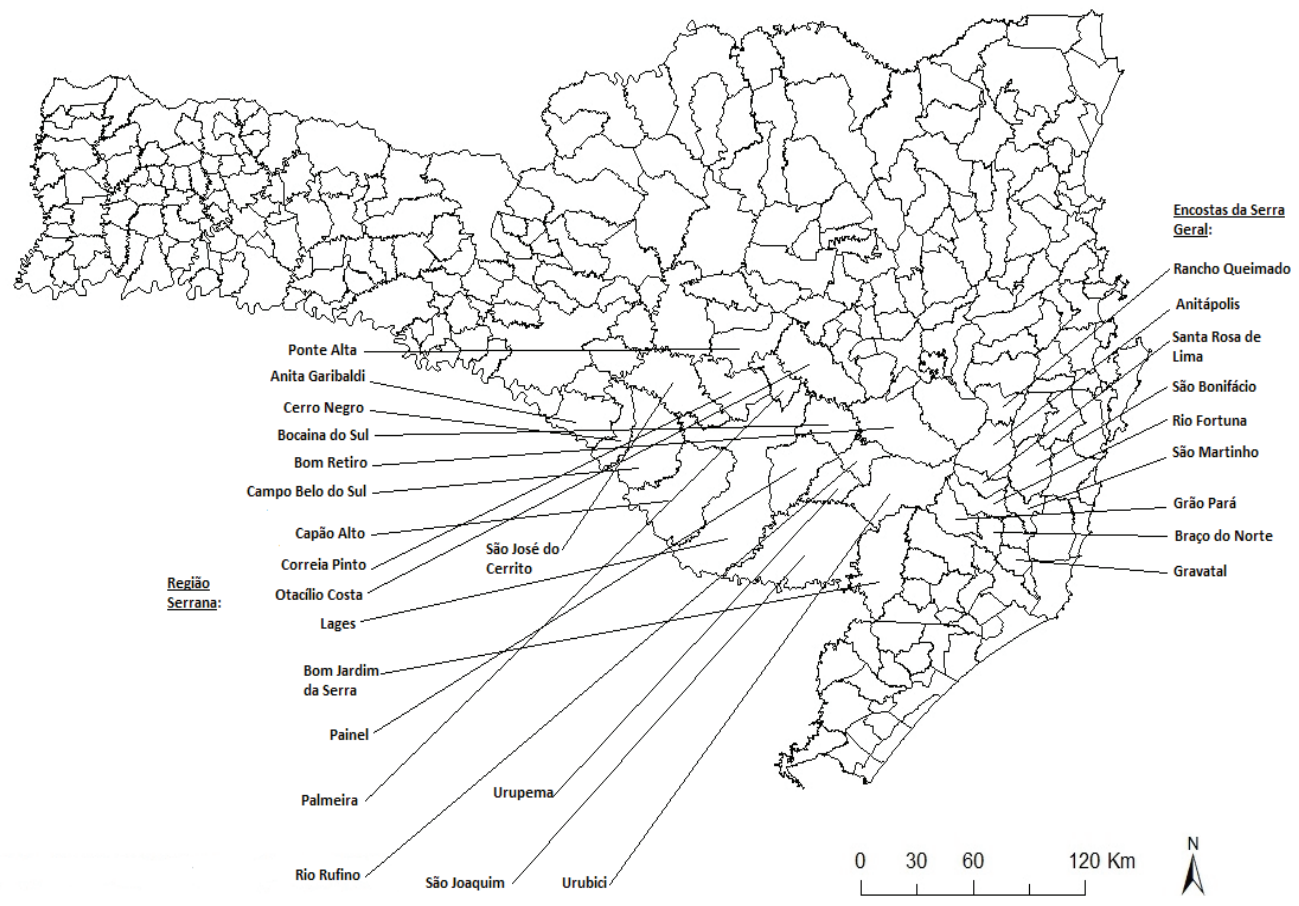

Fonte: elaborado pelo autor sobre base cartográfica do Instituto Brasileiro de Geografia e Estatística

\subsubsection{Agroturismo nas Encostas da Serra Geral}

Boa parte da área relativa às Encostas da Serra Geral apresenta recursos paisagísticos e ambientais típicos da Mata Atlântica e registra a predominância de pequenas e médias propriedades. A agricultura é a base da economia, historicamente. A fumicultura adquiriu destaque nos anos 1980, por estímulos de empresas de tabaco, 
e a pecuária leiteira, seguida da produção de laticínios, enraizou-se na década de 1990, após o declínio da primeira atividade. Mas foi a orientação rumo à agroecologia, primeiramente na produção de laticínios e, logo depois, envolvendo outros tipos de produtos, que marcou a trajetória local, salientam, entre outros, Müller (2001) e Oliveira (2004).

Quadros técnicos de diversas instituições participaram desse processo de introdução e difusão da agroecologia. Cabe mencionar, principalmente, a Universidade Federal de Santa Catarina, a Empresa de Pesquisa Agropecuária e Extensão Rural de Santa Catarina, o Centro de Estudos e Promoção da Agricultura em Grupo e prefeituras da área, principalmente do município de Santa Rosa de Lima.

Teve importância a criação, em 1996, por algumas famílias de produtores, da Associação dos Agricultores Ecológicos das Encostas da Serra Geral (AGRECO). A rápida multiplicação dos participantes nessa entidade certamente refletiu o entendimento, na esfera local, de que a produção agroecológica tinha viabilidade. Mas não deixou de contribuir o anúncio de possibilidades de financiamento para pequenas indústrias rurais com recursos oriundos do Banco Nacional de Desenvolvimento Econômico e Social (BNDES). Lograram sucesso nas candidaturas a esses recursos, como assinala Guzzatti (2010), vários pedidos contemplando atividades de abate de suínos e outros animais pequenos, seguido do processamento da carne. O mesmo se deu com atividades ligadas ao beneficiamento de hortaliças, assim como à produção de mel, de derivados da cana de açúcar, de queijo e outros derivados de leite e de pães e outros itens do mesmo gênero.

Paralelamente intensificou-se o debate, no âmbito do fórum de Desenvolvimento dos Pequenos Municípios das Encostas da Serra Geral, sobre a promoção do desenvolvimento local, ganhando corpo e vingando a estratégia do turismo rural. Isso culminou na criação da Associação de Agroturismo Acolhida na Colônia, em 1999, com inspiração na francesa Accueil Paysan e atuante em municípios de várias regiões catarinenses. $\mathrm{O}$ agroturismo foi a modalidade privilegiada, em sintonia com a presença da agroecologia na área (GELBCKE, 2006).

Pesquisa realizada por Macedo (2012), com levantamento direto de dados e informações num dos principais municípios envolvidos com agroturismo nas Encostas da Serra Geral - Santa Rosa de Lima (SRL) - , fornece uma boa ilustração sobre o sentido dessa atividade como possibilidade de desenvolvimento em áreas rurais. Esse município dista cerca de $120 \mathrm{~km}$ da capital de Santa Catarina e possui pouco mais de 2.000 habitantes, a grande maioria habitando o meio rural.

O referido estudo ocorreu no final de 2012, envolvendo cinco propriedades de agricultura familiar que praticavam agroecologia e agroturismo. Todas realizavam produção primária, transformação industrial de produtos primários e atividades de hospedagem ou alimentação. Diversos itens, entre eles mel e subprodutos da cana de açúcar, apresentavam certificação de origem agroecológica, e sua comercialização ocorria, em boa parte, por meio da estrutura da AGRECO. Práticas envolvendo a elaboração de conservas e a fabricação de doces, cucas e mesmo licores eram 
desenvolvidas em esquemas de consórcios. A produção agrícola, abrangendo, por exemplo, feijão e diversos outros itens, tinha uma tripla destinação: a subsistência, a comercialização e o abastecimento das atividades agroturísticas.

Essas propriedades - todas associadas à Acolhida na Colônia, mas nem todas à AGRECO - tinham recebido investimentos em instalações novas, a reboque do crescimento do fluxo de turistas, que inicialmente eram acomodados nas próprias residências dos agricultores. Observe-se que o engajamento no agroturismo (e na agroecologia) significava uso de uma mão de obra basicamente familiar. Mas não eram incomuns as manifestações de sentido comunitário na esfera do trabalho: acontecia também mobilização de vizinhos para auxílio nas tarefas de recepção de visitantes em momentos de maior demanda (como no preparo de refeições e nos serviços vinculados, por exemplo).

Era possível perceber, de fato, algum sentido de cooperação e solidariedade nas relações entre os proprietários, manifestadas, sobretudo, quando ocorriam consultas pela central de reservas da Acolhida na Colônia: a indisponibilidade de vagas numa propriedade provocava imediata indicação de outras pousadas da área que se sabia não estarem lotadas. Todavia, não se deixou de assinalar, em algumas entrevistas, que as iniciativas de natureza coletiva deveriam ser muito mais promovidas. Isso poderia resultar, entre outras coisas, em aquisições conjuntas de itens diversos pelas famílias, representando vantagens no que concerne aos preços, certamente mais favoráveis nessas circunstâncias.

O agroturismo tinha importância para a renda familiar. A representatividade variou de $30 \%$ a $80 \%$ da renda total, conforme o levantamento de Macedo (2012). A venda de produtos agroecológicos, primários ou transformados, e rendas de aposentadoria e pensões preenchiam o restante da renda nas propriedades pesquisadas, com variações de participação. De toda maneira, foi unânime entre os entrevistados a avaliação de que a orientação para a agroecologia e, principalmente, a diversificação das atividades rumo ao agroturismo, representaram melhoria das condições locais. Contudo, o pequeno número de propriedades visitadas por Macedo (2012) não autoriza imaginar que este seja um quadro geral.

Seja como for, essa experiência pode ser considerada uma ilustração sobre a importância do território, com seus recursos de várias ordens, para o desenvolvimento em meio rural. Serve, portanto, como ilustração possível no debate sobre o desenvolvimento territorial rural, conforme apresentado, em seus contornos amplos, no início do artigo. Como assinalado, a diversificação das atividades, para além da agricultura, e a valorização dos atributos dos territórios, incluindo a cultura - o que pressupõe considerar a importância da história - , no marco de relações tingidas de espírito colaborativo, são aspectos importantes nessa maneira de pensar e promover tal desenvolvimento. 


\subsubsection{Agroturismo nos hoteis fazenda e pousadas da Região Serrana}

Desde meados dos anos 1980, a Região Serrana de Santa Catarina registra destacada trajetória turística. Essa experiência escora-se, entre outras coisas, em recursos paisagísticos e aspectos climáticos que atraem, por exemplo, pelo frio e a possibilidade de neve. Têm igualmente influência os aspectos socioculturais, incluindo a gastronomia, mostrando que essa base turística é indissociável não só dos atributos naturais, mas também dos vários aspectos da atmosfera agrária, incluindo produção e modo de vida, inseparáveis da história e da cultura.

Nessa região a população habita majoritariamente o meio rural, com situações de redução demográfica, nas décadas recentes, que evidenciam uma situação de origem de fluxos migratórios. A precariedade das condições de vida, ligada à histórica limitação das oportunidades de emprego, subjaz a esse quadro. Sem qualquer exceção, os municípios exibem renda per capita inferior - e mesmo muito inferior - à média estadual. Há certa homogeneidade entre os municípios, indicando razoável equilíbrio intrarregional, mas o contexto é de baixo nível de desenvolvimento, muito inferior à média de Santa Catarina.

$\mathrm{Na}$ estrutura produtiva destaca-se a fruticultura de clima frio, sobressaindo o cultivo de maçã. Também são importantes as atividades de reflorestamento, extração de madeira, agropecuária (gado bovino e ovino) e lavouras (feijão, hortaliças). Pode-se assinalar o mesmo sobre o cultivo de vime, a produção de kiwi e a criação de trutas, e ainda a produção de papel e celulose, sem deixar de fora uma vitivinicultura de altitude que já chama a atenção.

A presença da pecuária extensiva é multissecular, desde os processos ligados ao ciclo do ouro no Brasil, no século XVIII, e se distribui tanto nos campos de Lages quanto no planalto de São Joaquim, áreas de fazendas centenárias. Tudo isso forjou a cultura regional, entre cujas evidências figuram as manifestações gastronômicas e o binômio tropeirismo-gauchismo, com seu folclore e narrativas de cunho lendário.

Em termos físicos e naturais, deve-se sublinhar a grande altitude dos municípios, que registram as temperaturas mais baixas do Brasil, um atributo básico da atratividade turística da região, também estribada em estruturas paisagísticas com escarpas, mesetas, platôs, vales e grandes superfícies de planalto com perfil ondulado. Esse conjunto físico-natural e histórico-cultural constitui um grande atrativo do turismo regional, motivando ações de valorização e aproveitamento. Um reflexo foi o reconhecimento das possibilidades locais pelo Ministério do Turismo: o município de São Joaquim passou a figurar entre os destinos turísticos da Região Sul do Brasil classificados como alvos prioritários de medidas objetivando o alcance de padrão internacional de qualidade (LAGE, 2007).

Dois tipos principais de equipamentos marcam o agroturismo da região: hoteis fazenda, situados em maior número na parte mais ocidental, e pousadas, com forte presença notadamente no lado mais montanhoso, embora também aqui existam alguns hotéis fazenda, além de resorts. 
Nos hoteis fazenda, o fluxo turístico é maior nas férias de verão e de inverno, mas há demanda também entre abril e junho, oriunda de várias regiões de Santa Catarina e de outros estados (com alguns registros de estrangeiros). A atividade atingiu certa expressão econômica em algumas propriedades, onde conservar e promover as atividades agropecuárias tradicionais é importante não só pelo que significam para a renda da propriedade, diretamente, mas também por suprirem boa parte das condições (referentes à alimentação e ao lazer) que permitem a prática turística.

Assim, nesses equipamentos o agroturismo proporciona oportunidades de trabalho também na agropecuária, ao lado do que permite de forma direta. A mão de obra utilizada é tanto familiar quanto contratada, mas não se pode falar em efetiva contribuição em termos de emprego: em vários casos o contingente realmente engajado parece bastante reduzido, lançando-se mão de moradores das vizinhanças ocasionalmente, durante os picos de demanda turística.

As atividades tradicionais dessas propriedades são importantes para o turismo também porque integram o conjunto de atrativos da região. Uma reportagem sobre Lages em jornal de circulação estadual, em Santa Catarina, destacou que a programação turística dos hoteis fazenda "[...] inclui vivenciar as lides campeiras de uma fazenda de verdade [...]” (DIÁRIO CATARINENSE, 2007, p. 46). A presença de tal estilização no marketing dessas formas de hospedagem sugere que essa imagem seduz habitantes urbanos em busca de práticas e ambientes que representem contraste com o seu cotidiano.

$\mathrm{Na}$ parte mais oriental da região têm destaque as pousadas rurais, em regra com perfil familiar (BATHKE, 2002). No envolvimento com o agroturismo observado na porção mais montanhosa, há vínculos que atingem organizações não governamentais, sindicatos e associações e órgãos da administração pública local (ALBUQUERQUE, 2004). Fazem parte as iniciativas para promover o Arranjo Produtivo Local (APL) de Turismo da Serra Catarinense, criado no início de 2007 no âmbito do Programa SEBRAE de Turismo. Já nos primeiros anos, esse APL aglutinando dezenas de empreendimentos em vários municípios, entre hoteis, pousadas e restaurantes - parecia resultar em aprimoramentos na gestão dos negócios, com avanços em profissionalização e nas inter-relações no trade turístico local (SEBRAE/SC 2007a).

$\mathrm{O}$ crescimento da vitivinicultura nessa área passou a contribuir para o turismo. Resultou desse processo (contribuindo para fortalecê-lo) a criação, em 2005, da Associação Catarinense dos Produtores de Vinhos Finos de Altitude (ACAVITIS), com dezenas de associados na própria região (a maioria) e também no meio oeste catarinense. Quando foi criado o mencionado APL, esperava-se que as relações entre essa atividade e o turismo se ampliassem: declarou-se que as ações de "[...] apoio ao turismo na Serra Catarinense [...iriam] se integrar ao projeto voltado ao desenvolvimento da vitivinicultura de altitude na região" (SEBRAE/SC, 2007b, s/p), na "[...] expectativa de que a vitivinicultura venha a se tornar mais um elemento de atração de turistas [...]” (CORDEIRO, 2006, p. 63). 


\section{Considerações finais}

As transformações ocorridas no meio rural em diferentes países, com proliferação de atividades que representam novas formas de uso dos recursos naturais, ampliam o escopo das oportunidades de geração de renda e trabalho e provocam mudanças inclusive no perfil populacional - tudo isso desfavorecendo clivagens analíticas do tipo rural-urbano - , fizeram o território erigir-se em dimensão privilegiada para a reflexão sobre o desenvolvimento e para a sua promoção nesses contextos. O desenvolvimento territorial rural ganhou espaço, desse modo, na agenda do desenvolvimento em meio rural, conforme evidenciado em pesquisas e iniciativas de política com respeito a numerosas realidades nacionais e regionais.

Sistemas agroalimentares localizados e agroturismo referem-se a feixes de atividades, desdobradas no meio rural (embora com transbordamentos), que representam ilustrações dos processos situados na base da "emergência" do território, e, simultaneamente, que admitem abordagens formuladas à luz do debate sobre o desenvolvimento territorial rural. Conforme observado na caracterização geral e nas experiências brasileiras tangenciadas no artigo, combinam-se, em ambos os tipos de manifestação, diferentes práticas e formas de conhecimentos, além da valorização de recursos com conteúdo histórico, cultural, paisagístico e ambiental, quer dizer, de atributos territoriais.

No tocante às ilustrações relativas a estudos inspirados na ideia de sistema agroalimentar localizado, essa combinação envolve, por exemplo, no cultivo de ostras e mexilhões em Santa Catarina, a qualidade do litoral desse estado e a herança sociocultural de várias comunidades pesqueiras, em que sobressaem conhecimentos sobre marés e outros aspectos enraizados nas interações sociais. Na produção de queijo em Nossa Senhora da Glória, em Sergipe, aqueles traços relacionam-se a uma longa trajetória pecuarista voltada ao leite e às pequenas queijarias artesanais, base, inclusive, para posterior inovação em produto. No que tange ao marolo em Alfenas (Minas Gerais), uma cultura alimentar que tem nesse fruto um importante ingrediente e que envolve numerosos pequenos produtores, constituiu alicerce sobre o qual se logrou atingir o plano do processamento, com agregação de valor. E no que concerne à carne bovina na Campanha Meridional Gaúcha, a história e a cultura dos pampas, com forte presença da pecuária de corte e um bioma bastante favorável, sustentaram os avanços exibidos na disponibilidade de produto com a qualidade destacada no estudo.

Quanto ao agroturismo, envolvendo tanto as propriedades agrícolas familiares e as pequenas pousadas das Encostas da Serra Geral, quanto os hoteis fazenda e as pousadas da Região Serrana, tudo em Santa Catarina, igualmente recursos territoriais específicos subjazem às possibilidades abertas ao desenvolvimento rural. Base paisagística e natural, de um lado, e elementos históricos e culturais, de outro, mostram-se indissociáveis do que se conseguiu atingir nessa modalidade turística, inclusive em relação ao surgimento e operação de instituições como as assinaladas AGRECO e Accueil Paysan. 
O papel que as "estruturas” representadas pelos sistemas agroalimentares localizados e pelo agroturismo podem desempenhar, na contribuição para o desenvolvimento dos ambientes implicados, deveria repercutir junto às esferas institucionais e políticas que têm no meio rural o foco das suas ações de estímulo e apoio. Suporte técnico e financeiro, manejado com base em acompanhamento permanente dos problemas e necessidades, e promoção de comportamentos e iniciativas aptos a propiciar melhores resultados coletivos, deveriam figurar no centro das atenções no plano governamental e institucional, em diferentes níveis de atuação. A observação de diferentes experiências, inclusive no plano internacional, detectando acertos e equívocos no trato com as questões relacionadas ao assunto, haveria de inspirar, possivelmente, medidas condizentes a serem adotadas em cada caso.

\section{Referências}

ABRAMOVAY, R. O capital social dos territórios: repensando o desenvolvimento rural. Economia Aplicada, v. 4, n 2, p. 379-397, 2000.

ABRAMOVAY, R. A dimensão territorial do desenvolvimento. Gazeta Mercantil, p. A-3, 12-15 abr. 2001.

ABRAMOVAY, R. Desenvolvimento rural territorial e capital social. In: SABOURIN, E.; TEIXEIRA, O. (Org.). Planejamento do desenvolvimento dos territórios rurais: conceitos, controvérsias e experiências. Brasília: UFPB/CIRAD/EMPBRAPA, 2002, p. 113-128.

ABRAMOVAY, R. O futuro das regiões rurais. $2^{\mathrm{a}}$ ed. Porto Alegre: Ed. da UFRGS, 2009.

ALBUQUERQUE, I. C. O papel do ecoturismo no Município de Urubici - SC. 2004. Dissertação (Mestrado em Engenharia Ambiental) - Universidade Federal de Santa Catarina, Florianópolis, 2004.

BATHKE, M. E. M. O turismo sustentável rural como alternativa complementar de renda à propriedade agrícola. Estudo de caso - Fazenda Água Clara - São Joaquim - SC. 2002. Dissertação (Mestrado em Engenharia de Produção) - Universidade Federal de Santa Catarina, Florianópolis, 2002.

BRASIL. Ministério do Desenvolvimento Agrário. Referências para o desenvolvimento territorial sustentável. Brasília: CONDRAF, NEAD, 2003. [Textos para discussão, 4] 

H. N. Lins - Desenvolvimento territorial rural: alguns termos do debate, sistemas ...

CAVACO, C. Turismo rural e desenvolvimento local. In: RODRIGUES, A. A. B. (Org.). Turismo e geografia: reflexões teóricas e enfoques regionais. $2^{\text {a }}$ ed. São Paulo: Hucitec, 1999, p. 94-121.

CERDAN, C., SAUTIER, D. Réseau localisé d'entreprises et dynamique territoriale: le bassin laitier de Gloria (Nordeste Brésil). In: MOITY-MAÏZI, P. et alii (Eds.). Systèmes agroalimentaires localisés: terroirs, savoir-faire, innovations. Versailles: INRA Editions, 2001.

CORDEIRO, W. A vitivinicultura em São Joaquim - SC: uma nova atividade no município. 2006. Dissertação (Mestrado em Agroecossistemas) - Universidade Federal de Santa Catarina, Florianópolis, 2006.

DIÁRIO CATARINENSE. Serra e meio-oeste. 6 nov. 2007 (Suplemento).

FAVARETO, A. As tentativas de adoção da abordagem territorial do desenvolvimento rural - lições para uma nova geração de políticas públicas. Raízes, v. $28, \mathrm{n}^{\circ} 1$ e 2, p. 52-62, jan. 2009-jun. 2010.

FAVARETO, A. Um contraponto à tese da "argentinização" do desenvolvimento rural no Brasil. In: BUAINAIN, A. M.; ALVES, E.; SILVEIRA, J. M. da; NAVARRO, Z. (Ed.). O mundo rural no Brasil do século 21: a formação de um novo padrão agrário e agrícola. Brasília: Embrapa, 2014, p. 1.101-1.124.

GELBCKE, D. L. Agroturismo e produção no espaço nas encostas da Serra Geral: entre a idéia e a prática. 2006. Dissertação (Mestrado em Geografia) - Universidade Federal de Santa Catarina, Florianópolis, 2006.

GUZZATTI, T. C. O agroturismo como elemento dinamizador na construção de territórios rurais: o caso da Associação de Agroturismo Acolbida na Colônia em Santa Rosa de Lima (SC). 2010. Tese (Doutorado em Geografia) - Universidade Federal de Santa Catarina, Florianópolis, 2010.

KAGEYAMA, A. Desenvolvimento rural: conceito e medida. Cadernos de Ciência E Tecnologia, v. 21, no 3, p. 379-408, set./dez. 2004.

LAGE, J. Turismo elege 65 destinos “internacionais". Folha de S. Paulo, p. B16, 1 set. 2007.

LINS, H. N. Sistemas agroalimentares localizados: possível "chave de leitura" sobre a maricultura em Santa Catarina. Revista de Economia e Sociologia Rural, v. 44, $\mathrm{n}^{\circ}$ 2, p. 313-330, abr./jun. 2006. Crossef http://dx.doi.org/10.1590/S010320032006000200008 
MACEDO, D. B. Santa Rosa de Lima - SC: uma discussão sobre opções em termos de desenvolvimento em nível territorial. 2012. Monografia (Graduação em Ciências Econômicas) - Universidade Federal de Santa Catarina, Florianópolis, 2012.

MALAFAIA, G. C.; BARCELLOS, J. O. J. Sistemas agroalimentares locais e a visão baseada em recursos: reconstruindo vantagens competitivas para a carne bovina gaúcha. Revista de Economia e Agronegócio, v. 5, nº 1, p. 25-49, 2007.

MORA, J.; SUMPSI. J. M. Desarrollo rural: nuevos enfoques y perspectivas. Santiago de Chile: FAO-FODEPAL, 2003.

MÜLLER, J. M. Do tradicional ao agroecológico: as veredas das transições - o caso dos agricultores familiares de Santa Rosa de Lima/SC. 2001. Dissertação (Mestrado em Agroecossistemas) - Universidade Federal de Santa Catarina, Florianópolis, 2001.

NAVARRO, Z. Desenvolvimento rural no Brasil: os limites do passado e os caminhos do futuro. Estudos Avançados, v. 15, no 43, p. 83-100, 2001. Crossef http:// dx.doi.org/10.1590/S0103-40142001000300009

NAVARRO, Z.; BUAINAIN, A. M.; ALVES, E.; SILVEIRA, J. M. de. Introdução. O mundo rural brasileiro: interpretá-lo (corretamente) é preciso. BUAINAIN, A. M.; ALVES, E.; SILVEIRA, J. M. da; NAVARRO, Z. (Ed.). O mundo rural no Brasil do século 21: a formação de um novo padrão agrário e agrícola. Brasília: Embrapa, 2014, p. 35-75.

OLIVEIRA, B. M. L. de. A produção de alimentos orgânicos pela rede de pequenas agroindústrias familiares da AGRECO em Santa Rosa de Lima e Rio Fortuna - SC. 2004. Dissertação (Mestrado em Economia) - Universidade Federal de Santa Catarina, Florianópolis, 2004.

ORTEGA, A. C. Desenvolvimento territorial rural no Brasil: limites e potencialidades dos CONSADS. Revista de Sociologia e Economia Rural, v. 45, n 2, p. $275-$ 300, abr./jun. 2007. erossef http://dx.doi.org/10.1590/S0103-20032007000200003

PECQUEUR, B. Qualité et développement territorial: l'hypothèse du panier de biens et de services territorialisés. Économie Rurale, v. 261, p. 37-49, jan.-fév. 2001.

PECQUEUR, B. O desenvolvimento territorial: uma nova abordagem dos processos de desenvolvimento para as economias do Sul. Raízes, v. 24, n ${ }^{\circ} 1$ e 2, p. 10-22, jan./dez. 2005. 
PECQUEUR, B. De l'exténuation à la sublimation: itinéraire d'une notion et de ses déclinaisons. VANIER, M. (Dir.). Territoires, territorialité, territorialisation: controverses et perspectives. Rennes: Presses Universitaires de Rennes, 2009a, p. 205-209.

PECQUEUR, B. A guinada territorial da economia global. Política E Sociedade, $\mathrm{n}^{\mathrm{O}}$ 14, p. 79-105, 2009b. rossef http://dx.doi.org/10.5007/2175-7984.2009v8n14p79

RAY, C. A mode of production for fragile rural economies: the territorial accumulation of forms of capital. Journal of Rural Studies, v. 18, p. 225-231, 2002. Erossef http://dx.doi.org/10.1016/S0743-0167(02)00003-7

REQUIER-DESJARDINS, D. Multifonctionnalité, territoire et secteur agroalimentaire: une approche par les "systèmes agroalimentaires localisés". Cabiers $d u$ C3ED, Université de Versailles, nº 02-01, Juin 2002.

REQUIER-DESJARDINS, D., RODRIGUEZ, G. Limpact environnemental de l'agro-industrie de la panela: agriculture durable et système agroalimentaire localisé. 7ème CONFERENCE DE L'ASSOCIATION INTERNATIONALE D’ECONOMIE ECOLOGIQUE, Sousse (Tunísia), Mar. 2002.

REZENDE, M. L.; CÂNDIDO, P. A.; MALAFAIA, G. G. Sistema agroalimentar localizado: uma abordagem para o marolo na região de Alfenas, Minas Gerais. Scientia Plena, v. 8, n 8, p. 1-7, 2012.

SABOURIN, E. Dispositivos coletivos de apoio à produção e dinâmicas territoriais. Raízes, v. 28, no 1 e 2, p. 154-165, jan. 2009-jun. 2010.

SÁNCHEZ-ZAMORA, P.; GALLARDO-COBOS, R.; CEÑA-DELGADO, F. Rural areas face the economic crisis: analysing the determinants of successful territorial dynamics. Journal of Rural Studies, v. 35, p. 11-25, 2014. Crossef http://dx.doi. org/10.1016/j.jrurstud.2014.03.007

SCHNEIDER, S. A abordagem territorial do desenvolvimento rural e suas articulações externas. Sociologias, Ano 6, nº 11, p. 88-125, jan.-jun. 2004.

SCHNEIDER, S. Situando o desenvolvimento rural no Brasil: o contexto e as questões em debate. Revista de Economia Política, v. 30, $\mathrm{n}^{\mathrm{o}} 3$, p. 511-531, jul.-set. 2010. rossef http://dx.doi.org/10.1590/S0101-31572010000300009

SEBRAE/SC. Consultorias melhoram APL de Turismo da Serra Catarinense. Notícias para MPE's, 2007a. Inclusão: 20/08/2007. Obtido em: www.sebrae-sc.com.br/ Acesso em: 3 nov. 2007. 
SEBRAE/SC. Simpósio debate qualidade dos vinhos catarinense. Notícias para MPE's, 2007b. Inclusão: 05/11/2007. Obtido em: www.sebrae-sc.com.br/ Acesso em: 3 nov. 2007

VEIGA, J. E. Desenvolvimento territorial: do entulho varguista ao zoneamento ecológico-econômico. Babia Análise E Dados, v. 10, nº 4, p. 193-206, 2001.

VEIGA, J. E. A face territorial do desenvolvimento. Interações, v. 3, $\mathrm{n}^{\circ}$ 5, p. 5-19, set. 2002a.

VEIGA, J. E. Cidades imaginárias: o Brasil é menos urbano do que se calcula. Campinas: Autores Associados, 2002b.

Recebido em 07.01.16

Aprovado em 15.06.16 